\title{
Edukasyon bilang Tagpuan ng Katwirang Lungsod at Katwirang Lalawigan
}

Noel L. Clemente

\begin{abstract}
The city-province distinction is usually construed in economic terms: the city is the center of consumption and wealth, while the province the center of production and raw materials. In this paper, I propose that we can also draw the distinction epistemologically; instead of distinguishing between city-dwellers and provincedwellers, we can talk about city-minded and province-minded people. In this perspective, we discover the crucial position of education as the paradoxical interplay of the city mentality and province mentality. After examining this "paradox of education" as witnessed in Philippine history, especially during the Spanish and American occupations, I suggest that we can resolve the paradox by developing our system of education towards a more "nationalistic education," as per Renato Constantino.
\end{abstract}

Keywords: Constantino, Rodriguez, city, education

$\mathrm{K}$ aramihan, kung hindi man lahat, ng mga lungsod sa kasaysayan ng mundo ay naitaguyod bílang sentro ng kalakalan. Dahil may labis na likás-yaman at produktong hindi kailangang gugulin agad-agad, iniimpok ito, at ikinakalakal, at nagkakaroon ng kíta, na kailangang tipunin sa isang kabisera: ang lungsod. Kayâ naman, maraming sosyologo ang gumuguhit ng pagkakaiba ng lungsod at lalawigan sa ekonomikong batayan.

Subalit maaari rin nating pagtambisin ang lungsod at lalawigan batay sa epistemolohikong perspektiba. Hindi natin maikakailang malaki ang pagkakaiba ng uri ng pangangatwiran ng mga tagalungsod at tagalalawigan. Kung tatanawin natin ang kalagayan ng mga lungsod ng Filipinas sa ganitong pananaw, ${ }^{1}$ matutuklasan nating edukasyon ang siyang namamamagitan sa dalawang magkaibang katwiran.

1 Hindi ko sinasabing epistemolohiko ang angkop o mas tamang batayan ng distinksiyon ng lungsod at lalawigan. Hindi ko pangunahing haka sa papel na ito ang paglapat ng epistemolohikong lente, sa halip, isa itong palagáy ng aking punto: kung pagtatambisin natin

(c) 2016 Noel L. Clemente

http://www.kritike.org/journal/issue 18/clemente june2016.pdf

ISSN 1908-7330

(cc) BY-NC-ND 
Sa papel na ito, nais kong suriin ang kabalintunaang kaakibat ng edukasyon bílang tagpuan ng katwirang lungsod at katwirang lalawigan. Sa unang bahagi, ipapaliwanag ko ang gamit ng katwiran bílang balangkas ng pag-unawa ng isang tao, at ipapakita ang sapantaha kong magkasalungat nga ang katwiran ng lungsod at lalawigan. Sa ikalawang bahagi, ilalatag ko ang kabalintunaan ng edukasyon na kalakip ng pagiging tagpuan ng dalawang katwiran, na matutunghayan natin sa kasaysayan hanggang kasalukuyan. Bilang pagtatapos, magmumungkahi ako ng mga maaari nating gawin upang samantalahin itong posibilidad ng edukasyon sa pagtawid sa dalawang katwiran, tungo sa tinatawag ni Renato Constantino na "makabayang edukasyon."

\section{Ang Lungsod at Lalawigan bílang Magkaibang Katwiran}

\section{Katwiran bílang Balangkas ng Pag-unawa}

Karaniwang ginagamit ang salitang "katwiran" bílang paliwanag ng isang bagay. Halimbawa, hinihingan ng mga guro ng katwiran ang mga magaaral na lumiliban sa klase. Mas halata ang ganitong gamit ng katwiran sa mga araling pang-akademiko: grabedad, halimbawa, ang katwiran ng pagkahulog ng anumang bagay sa lupa matapos bitiwan sa ere. Kadalasan, iniuuwi sa agham at matematika ang mga "makatwirang" pahayag: makatwiran ang anumang maipapaliwanag ng pag-eeksperimento at pagbibiláng. Samantala, hindi itinuturing na makatwiran ang mga pamahiin at mga relihiyon, dahil wala silang siyentipikong batayan.

Higit na malawak ang saklaw ng "katwiran" na gagamitin ko sa papel na ito. Ayon kay Agustin Rodriguez, ang katwiran ang siyang "nagbabalangkas ng ating praktikal at teoretikal na pag-unawa sa mundo, sa ating pagkilala ng mabuti sa nararapat." 2 Dalawang antas ang inilawak ng ganitong depinisyon sa palasak na pag-unawa natin sa "katwiran" na ipinaliwanag ko sa nakaraang talata. Una, hindi lámang yaong mga siyentipikal at matematikal ang maituturing na makatwiran. Totoo namang makatwiran ang agham at matematika, ngunit kailangang igiit na makatwiran lámang ito para sa mga táong nakauunawa at nag-iisip sa ganitong balangkas. At natural ding ituturing nilang hindi makatwiran yaong mga hindi sumasang-ayon sa kanilang katwiran. Ngunit sa teoriya ni Rodriguez, hindi lang agham at matematika ang makatwiran. Tingnan natin, bílang halimbawa, ang mga pamahiin ng mga katutubong Filipino. Dahil

\footnotetext{
ang dalawa batay sa kanilang pag-iisip, kritikal ang edukasyon bílang tagpuan ng dalawang katwiran.

2 Agustin Martin G. Rodriguez, May Laro ang Diskurso ng Katarungan (Quezon City: Ateneo de Manila University Press, 2014), 116.

(c) 2016 Noel L. Clemente

http://www.kritike.org/journal/issue 18/clemente june2016.pdf

ISSN 1908-7330
}

(c) ) BY-NC-ND 
naniniwala sila sa iba't ibang espirito at diyos, ipinapaliwanag nila ang kanilang mga karanasan batay sa mga diyos na ito. Sa gayon, ang kanilang relihiyon ang kanilang katwiran. Kung may nagkasakít na bata, halimbawa, naniniwala silang may nagambala o napinsala silang espiritu, at bílang parusa, isinumpa ng espiritu ang katawan ng bata. Ganito nila inuunawa ang mga karamdaman. Hindi natin sila masisisi, dahil wala pa naman silang kaalaman sa mga bacteria at virus, at ang tanging batayan ng mga hindi nila maipaliwanag ay ang sobrenatural.

Ang ikalawang antas ng paglawak: hindi lamang intelektuwal o teoretikal ang saklaw ng "katwiran" ayon sa gámit ni Rodriguez; kabilang dito ang praktikal na dimensiyon. Kayâ naman, mahalagang aspekto ng katwiran ang sistema ng pagpapahalaga ng mga tao. ${ }^{3}$ Ginagabayan ng balangkas ng pagpapaliwanag ng tao sa kaniyang kapaligiran ang kaniyang pagpapasiya kung ano ang dapat at hindi dapat gawin. Dagdag sa halimbawa ko sa nakaraang talata, dahil nga ipinapaliwanag nila ang karamdaman bilang kaparusahan ng espiritung nagambala, nagbibigay sila ng alay para sa espiritu bílang kabayaran sa kanilang paggambala rito. Kung tatanggapin ng espiritu ang alay, naniniwala silang babawiin niya ang sumpa sa katawan ng bata, na ikagagaling nito.

Bago ako tumungo sa paglalarawan ng katwiran ng mga tagalungsod at ng mga tagalalawigan, nais kong banggitin ang isa pang mahalagang punto: isinisilang tayo sa isang katwiran; hindi natin ito pinipili. ${ }^{4}$ Sasabihin ni Martin Heidegger: itinapon tayo sa isang katwiran. Ipinanganak táyong kabilang sa isang kultura na may nakatatag nang katwiran, at minamana natin ang ganitong katwiran. At sapagkat nasanay táyong tanawin ang mundo at ating mga karanasan sa ating katwiran, hindi natin naiisip na may umiiral na ibang katwiran. Minsan, masaklap ngang kapag tiningnan na natin ang ibang katwiran, itinuturing natin siláng mali, o mas mababa kaysa ating katwiran. ${ }^{5}$

Bílang paglalagom, gagamitin ko ang "katwiran" sa papel na ito bílang balangkas ng teoretikal at praktikal na pag-unawa ng isang tao sa mundo. Itinatapon ang tao sa kaniyang katwiran, at sapagkat parati niyang tinitingnan ang katalagahan ayon sa kaniyang katwiran, nakakaligtaan niyang may umiiral na ibang katwiran, at kung makatagpo man siya ng ibang katwiran, madalas, itinuturing niya itong depektibo, kung hindi man mali.

\footnotetext{
${ }^{3}$ Ibid., 107-115. Ginamit ni Rodriguez ang pananaw ni Max Scheler ukol sa mga halaga bílang bumubuo sa aspekto ng kalooban.

${ }^{4}$ Ibid., 95. Igigiit ni Rodriguez na sa isang banda, pinipili rin natin ang ating katwiran, kapag nagkaroon tayo ng karanasang magtutulak sa atin upang kuwestiyonin at tanggihan ang nakagawiang katwiran. Hindi ko ikinakaila ang puntong ito, pero bílang paunang depinisyon sa gamit ko ng "katwiran," sapat na muna ang pagsabing hindi natin ito pinipili sa simula.

${ }^{5}$ Ibid., 96.
}

(C) 2016 Noel L. Clemente http://www.kritike.org/journal/issue 18/clemente june2016.pdf ISSN 1908-7330 


\section{Dalawang Magkaibang Katwiran ng Lungsod at Lalawigan}

Mas madaling mauunawaan ang "katwiran" ni Rodriguez sa mga kongketong halimbawa. Sa kaniyang pagpapaliwanag, nagbigay siya ng dalawang magkasalungat na katwiran na maaari nating ihalintulad mamaya sa katwirang lungsod at katwirang lalawigan.

Malaki ang pagpapahalaga ng mga táong relihiyoso sa kabanalan. Naniniwala siláng may (mga) umiiral na higit sa kanila, na mas makapangyarihan at mas tumatagal kaysa mga mortal. Iginagalang nila ang mga puwersang ito, kayâ naman naniniwala siláng hindi tao ang nagtatakda ng kahulugan at katalagahan. Samantala, mataas naman ang tingin ng mga táong sekular sa sangkatauhan. Para sa kanila, tao, at hindi mga diyos, anito, at espirito, ang siyang nagdidikta ng kahulugan. Naniniwala silang malaya ang tao na manipulahin ang kalikasan at panahon ayon sa kaniyang pagpapasiya ng ano ang mahalaga. ${ }^{6}$

Siyempre, hindi naman natin maiuuwi ang katwirang lungsod sa katwirang sekular, at ang katwirang lalawigan sa katwirang relihiyoso; mas malalim ang pagkakaiba sa pananaw sa kalawakan. Ngunit maaari nating simulan ang pagguhit ng dalawang katwiran sa halimbawang ito ni Rodriguez. ${ }^{7}$ Simulan natin sa katwirang lungsod. Bílang mga nakatira sa sentro ng kalakalan, at sa gayon sa sentro ng paggawa at pananalapi, may káya ang karaniwang tagalungsod. Minsan, higit pa sa may káya, maunlad ang kaniyang katayuan sa búhay. Dahil dito sa kakayahan niyang kumita ng pera at sa karanasan ng maginhawang búhay, malaki ang pagpapahalaga niya sa mga materyal na bagay. Kayâ naman, palasak sa lungsod ang kaisipang kumikiling sa kung ano ang mapagkakakitaan. Ito ang dahilan kung bakit sikát at kaakit-akit sa lungsod ang pagiging maalam sa pananalapi, sa medisina, o sa abogasya. Nakatuon sila sa pagkakaroon ng sapat na yaman, hindi lang upang mabuhay, kundi para maging "komportable" ang búhay: may sariling tirahan, kotse, at iba pang ari-arian. Samakatwid, maiuugnay natin ang katwirang sekular sa mga tagalalawigan: sapagkat hahamak sila upang kumita, naniniwala siláng tao-sila-ang may kapangyarihan sa mundo. ${ }^{8}$

Kasalungat nito ang katwirang lalawigan. Malayo sa kasukdulan ng impluwensiya ng ating mga mananakop, napanatili ng karamihan sa ating mga tagalalawigan ang kanilang mga katutubong tradisyon. Sa gayon,

${ }^{6}$ Ibid., 94.

7 Sa paglalarawan ng katwiran ng mga tagalungsod at ng mga tagalalawigan, hindi ko sinasabing ganito ang katwiran ng bawat isang tagalungsod o tagalalawigan. Inilalarawan ko lang ang nangingibabaw na uri ng pag-iisip ng dalawang pangkat ng taong nabanggit.

${ }^{8}$ Hindi ko sinasabing magkatumbas ang katwirang lungsod at katwirang sekular; sinasabi ko lang na magkaugnay sila; may mga aspektong magkakatulad, marahil.

(C) 2016 Noel L. Clemente

http://www.kritike.org/journal/issue 18/clemente june2016.pdf

ISSN 1908-7330

(c) BY-NC-ND 
maipagpapalagay nating makakalikasan at relihiyoso ang karaniwang tagalalawigan. ${ }^{9}$ Marami sa kanila ang tradisyonal na magsasaka $\mathrm{O}$ mangingisda, kayâ malaki ang pagpapahalaga nila sa lupa at karagatan. Payak ang kanilang materyal na búhay, at hindi sila nakikipagkumpetensiya sa mga ari-arian. Ginagalang din nila ang kanilang diyos at mga ninuno, at hitik ang kanilang kultura sa mga pamahiin.

Samakatwid, sa isang simplistikong pananaw, maaari nating sabihing materyalistiko at indibidwalistiko ang katwirang lungsod, samantalang relihiyoso at kolektibo ang katwirang lalawigan. Sa ganitong perspektiba, maaaring may mga naninirahan sa lungsod na may katwirang lalawigan (e.g., mga iskwater na namumuhay malapít sa mga pamilya at kamag-anak at kumakapit pa rin sa mga katutubong paniniwala at tradisyon) o mga tagalalawigang may katwirang lungsod (e.g., mga hacienderong nagpapasiya batay sa materyal na pagsasaalang-alang). Sa gayon, napagtatambis natin, hindi kung sino ang tagalungsod at tagalalawigan, kundi sino ang isip-lungsod at isip-lalawigan. ${ }^{10}$

Hindi ko hahamaking magbigay ng komprehensibong paglalarawan ng katwirang lungsod at katwirang lalawigan sa papel na ito. ${ }^{11}$ Sapat nang makita nating may umiiral na dalawang magkaibang katwiran na humahati sa kinikilala nating lungsod at lalawigan.

\section{IAng Kabalintunaan ng Edukasyon, Mula Noon Hanggang Ngayon}

Ngayong naipaliwag ko na ang epistemolohikong perspektiba ng pagtingin sa lungsod at lalawigan, matatatap nating nagtatagpo itong dalawang katwiran sa paaralan. ${ }^{12}$ Dala ng isang karaniwang batà ang katwirang lalawigan kapag pumasok siya sa paaralang nahubog na ng

9 Mas mailap ang ideya ng "karaniwang tagalalawigan" kaysa "karaniwang tagalungsod" sapagkat marami táyong magkakaibang lalawigan sa bansa, ngunit sasapat na ang ganitong paglalarawan sa pakay ng papel na ito.

10 Maaaring magtunog mapanghusga ang mga katagang "isip-lungsod" at "isiplalawigan" na para bang itong dalawa lang ang maaaring pagpilian at walang puwang sa bahagya. Bagaman may mga kilos at salita na mailap tukuyin kung katwirang lungsod at katwiran lalawigan ba ang pinagmulan, igigiit kong sa pangkalahatan, nakikilala naman natin ang pagkakaiba ng dalawang kaisipang ito.

${ }^{11}$ Maaaring palawigin ang pagtatambis ng katwirang lungsod at katwirang lalawigan kung titingnan ang kaibhan ng katwirang postmoderno na laganap sa Kanluran, at ang katwirang premoderno na umiiral sa bansa, ayon sa argumento ni Demeterio. See F.P.A. Demeterio III, "Our Premodernity and Their Tokens of Postmodernity: Reflections on the Philippine Condition," in Academia, < https://www.academia.edu/7340227/Our Premodernity and_their_Tokens_of_Postmodernity_Reflections_on_the_Philippine_Condition>, 21 March 2016.

12 Yaong mga pormal na paaralan, na sumasailalim sa DepEd at CHED ang tinutukoy ko rito. Kung tutuusin, hindi natin matatawag na "pormal na edukasyon" ang pag-aaral sa bahay dahil hindi estandardisado ang kaniyang inaaral doon.

(C) 2016 Noel L. Clemente

http://www.kritike.org/journal/issue 18/clemente june2016.pdf

ISSN 1908-7330

(cc) BY-NC-ND 
katwirang lungsod, sa tulong ng pagkakaroon ng standard curriculum ng DepEd at CHEd para sa lahat ng paaralan ng bansa. Sa gayon, tinuturuan ang mga isip-lalawigan na maging isip-lungsod, at dito nagkakaroon ng tunggalian ang dalawang katwiran.

Higit kong maipaliliwanag ang ganitong kabalintunaan ng edukasyon kung tutunghayan natin ang ebolusyon ng edukasyon mula ng itatag ito ng mga Kastila, hanggang samantalahin ito ng mga Amerikano, at hanggang sa kasalukuyang sistema ng edukasyon.

\section{Edukasyon bílang Panangga sa Pang-aabuso ng mga Kastila}

Karamihan ng mga lungsod sa Asya at mga bansang nasakop ng mga Europeo, kasama na ang Kamaynilaan, ay itinatag bilang sentro ng kalakalan ng kanilang mga mananakop. ${ }^{13}$ Upang tustusan ng mga Kastila ang pamamahala sa kanilang mga kolonya, pati na rin ang sari-saring digmaang kinasangkutan nila, kinailangan nilang kamkamin ang mga likas na yaman ng bansa. Pagkatapos pagtipon-tipunin ang mga katutubong Filipino mula sa kanilang barangay tungo sa mga reduccion, inalis nila ang karapatan ng mga katutubo sa lupa, at pinatawan nila ng malalaking buwis ang pagsasaka sa mga ito. Sapilitan din nilang binibili ang mga produkto ng mga indio ${ }^{14}-$ bansag nila sa mga Filipino-sa mas mababang halaga. Idagdag pa rito ang polo y servicios o 40 araw ng sapilitang paggawa kada taon, at ang buwis na hinihingi ng simbahan. Ganap na naitatag ang Maynila bilang lungsod nang gawin itong sentro ng kalakalan sa Kalakalang Galleon. ${ }^{15}$ Unti-unting nasira ang katutubong kultura ng mga Filipino, at tuluyang naihanay sa interes ng mga dayuhang Kastila ang itinatag na lungsod. ${ }^{16}$ Samakatwid, ang Maynila ay nasa teritoryong katutubo ngunit may katwirang dayuhan.

Kayâ naman, natatakot pag-aralin ng mga Kastila ang mga indio sapagkat natatakot siláng matuklasan ng mga ito ang kanilang kapalaluan. Wika ni Apolinario Mabini, "Kung ibig palagiin ng mga Español ang kanilang paghahari, kailangang pamalagiin nila ang kamangmangan at

${ }^{13}$ Alan Gilbert and Joseph Gugler, Cities, Poverty and Development: Urbanization in the Third World (New York: Oxford University Press, 1992), 17.

${ }^{14}$ Malalim ang epekto nitong derogatoryong bansag sa katwiran ng mga Filipino; dahil sa negatibo nitong kahulugan, bumaba ang tingin ng Filipino sa kaniyang sarili at tumaas ang kaniyang paghahangad na maging katulad ng kaniyang mananakop. See F.P.A. Demeterio III, "The Primitivization of the Indio Mind and the Explosion of Rationalities: The Politics of Knowledge in the Spanish Colonial Philippines," in Academia, $<$ https://www.academia.edu/7340242/The Primitivization of the Indio Mind and the Explos ion_of_Rationalities_the_Politics_of_Knowledge_in_the_Spanish_Colonial_Philippines $>, \quad 21$ March 2016.

15 Patricio N. Abinales at Donna J. Amoroso, State and Society in the Philippines (Mandaluyong City: Anvil Press, 2005), 60-62.

${ }^{16}$ Gilbert and Gugler, Cities, Poverty and Development, 18.

(C) 2016 Noel L. Clemente

http://www.kritike.org/journal/issue 18/clemente june2016.pdf

ISSN 1908-7330

(c) $)$ BY-NC-ND 
kahinaan ng mga Filipino."17 Taglay ang karunungang nakukuha sa paaralan, mas batid ng isang tao ang kaniyang mga karapatan at magiging maláy siya sakaling may nananamantala sa kaniya. Manapa, kung maalam ang mga indio sa sistemang ekonomiko o politikal ng mga banyaga, bakâ magkaroon pa sila ng pagkakataong makipagsabayan sa mga ito at makapamuhay nang matiwasay sa lungsod. Kung gayon, mas may dahilan ang mga katutubong mag-alsa laban sa mga mananakop, na siyang ayaw mangyari ng mga Kastila. Edukasyon ang nagsisilbing panangga laban sa pang-aabuso ng mga Kastila-dahil mamumulat ang indio sa katwirang dayuhan-kayâ naman hangga't maaari, hindi nila hinahayaang makapagaral ang mga indio.

Siyempre, hindi naman mapipigilan ng mga Kastila ang mga mayayamang indio na may kakayahang magbayad ng pangmatrikula, kung hindi man sa bansa, sa Europa. Maraming kabataan, kasama na si Dr. Jose Rizal, ang tumungo sa Europa nang makapag-aral sa pag-asang makamit ang susi mula sa kahirapan at kamangmangan. Ngunit mapapansing hindi nais nitong mga "propagandista" na mahiwalay ang Filipinas sa Espanya. Sa halip, isinusulong nilang maging opisyal na lalawigan ng Espanya ang bansa, nang sa gayon, magkaroon ng pantay na karapatan ang mga indio at Kastila sa teritoryo ng Filipinas. Asimilasyon, hindi kalayaan, ang hinihiling nila. Dito natin mapupuna ang isa pang bunga ng edukasyon-sapagkat nauunawaan ang katwiran ng banyaga, bahagya ring nagiging kabilang ang mga edukado sa katwirang hindi nauunawaan ng kanilang mga kababayang hindi edukado. ${ }^{18}$ Isipin mo na lang kung paano ipapaliwanag ng mga propagandista sa mga mahihirap nilang kababayan ang kanilang pagkiling sa asimilasyon, sa halip na ganap na kalayaan. Makikita ng huli ang nauna bílang kasapi na rin ng mga Kastila.

Bílang paglalagom, naging mahirap ang mga buhay ng mga Filipino sa pananakop ng mga Kastila dahil naging dayuhan sa kanila ang sistemang ginagalawan nila-hindi nila nauunawaan ang katwirang Kastila. Yaong mga may kakayahang pinansiyal ay nakapag-aral sa mga lungsod (maging sa mga lungsod ng Europa), upang makasabay sila sa sistemang dayuhan. Lulan ng edukasyon, naunawaan nga nila ang katwirang banyaga, na patúloy na banyaga sa kanilang mga kababayang hindi edukado. Samakatwid, may kaakibat na paglayo sa mga katutubo itong paglapit sa

\footnotetext{
${ }_{17}$ Apolinario Mabini, Ang Rebolusyong Filipino, trans. by Michael M. Coroza (Manila: Pambansang Komisyon sa Kultura at mga Sining, 2015), 12.

${ }^{18}$ Hindi ko sinasabing tama ang isa - sa asimilasyon at kalayaan - at mali ang isa pa. Sa halip, mahihiwatig sa dalawang ito ang kaibhan ng katwiran ng mga edukado at di-edukado. Kalayaan ang nanaisin ng mga isip-lalawigan na nakararanas ng marahas na pananamantala ng mga dayuhan, samantalang asimilasyon ang pipiliin niyong mga isip-lungsod na may kayamanan at karunungan, at nauunawaan na may posibilidad ng mapayapang pag-aareglo ng pamamahala.
} 
katwiran ng mga dayuhan.

\section{Edukasyon bílang Kasangkapan ng Pananakop ng mga Amerikano}

Makikita natin lalò ang ganitong balintunang kalakip ng edukasyon sa panahon ng mga Amerikano. Sa kasalukuyan, mapapansin nating mas malaki ang naging impluwensiya ng mga Amerikano kaysa mga Kastila sa ating pamumuhay; masdan mo pa lang ang wikang namamayani sa paaralan. Ano ang nagawa ng mga Amerikano sa apat na dekada na hindi nagawa ng mga Kastila sa mahigit tatlo't kalahating siglo? Edukasyon para sa lahat.

Kung ano ang ikinatakot ng mga Kastila sa pagpapaaral sa mga Filipino, ganoon ang ikinasigasig ng mga Amerikano sa pagtatatag ng mga pampublikong paaralan. Nagbalatkayo ang mga Amerikano bilang mga kaibigan, at nililok ang katwiran ng kabataang Filipino ayon sa Kanluraning agham, wika, at mga pagpapahalaga ng mga katutubo. ${ }^{19}$ Nag-aral ang mga katutubo hindi bílang Filipino, ngunit bilang kolonisado, na kailangang umayon sa interes ng mga "kaibigang" mananakop. ${ }^{20}$ Ang pinakamahalaga marahil na kasangkapan ng mga Amerikano ay ang pagturo sa kanilang wika; sa pagsasanay makinig, magbasa, magsalita, at magsulat sa Ingles, nagkaroon ng malinaw na pagtatambis sa mga edukado at sa mga masa. ${ }^{21}$

Lalòng naging maigting ang kabalintunaan ng edukasyon. Sa isang banda, malaya nang nakakapagtalastas at nakakasabay ang mga arál sa buong mundo, lalò na ang mundo ng Kanluran, dahil nauunawaan na nila ang Kanluraning katwiran.22 Sa kabilang banda, lalòng lumapad ang kalayuan ng mga edukado sa mga di-edukado, na kapuwa mga Filipino; naging dayuhan na sa masa ang mga arál. Higit pang napalalâ itong agwat ng komersiyalisasyon ng edukasyon. Bumaba kalaunan ang antas ng edukasyon sa mga pampublikong paaralan, samantalang naipon ang kalidad sa mga pribadong paaralan sa malaking halaga, na karaniwang nasa lungsod. ${ }^{23}$ Naging ginto na ang susi sa kahirapan; yaong mga masalapi lang ang may tiket sa magandang edukasyon, at sa banyaga at mas "maunlad" na katwiran.

Bukod sa intelektuwal na pagsasadayuhang nagaganap sa paaralan, nagkaroon din ng pagpapalaganap ng mga pagpapahalagang Amerikano sa tulong ng telebisyon at radyo. Nahawa ang mga Filipino pati na rin ang ibang

${ }^{19}$ Renato Constantino, "The Mis-education of the Filipino," in Journal of Contemporary Asia, 1:1 (1970), 22.

${ }^{20} \mathrm{Ibid} ., 24$.

${ }^{21}$ Ibid.

22 Ibid., 23.

${ }^{23}$ Ibid., 34.

(C) 2016 Noel L. Clemente

http://www.kritike.org/journal/issue 18/clemente june2016.pdf

ISSN 1908-7330

(c) BY-NC-ND 
mga kolonisado sa panlasa sa pananamit, pagkain, at paraan ng pamumuhay ng kanilang mga mananakop. Naging magkakamukha ang mga gusali, manggagawa, at mga kasangkapan, saanman sa mundo. ${ }^{24}$ Masisilayan natin ito sa kasalukuyan: halos lahat ay may mga smartphone na, o di kaya tablet at laptop. Sa pamamagitan ng mga bagay na ito, nakikibahagi táyo sa katwirang lungsod.

Sa kasamaang palad, hindi kasíng unibersal ng konsumerismong pagpapahalaga ang kakayahang magkaroon ng ganitong mga modernong kasangkapang. Samantalang namana ng lahat ang panlasa ng makabagong daigdig, kasama at lalò na ang mga nasa mahihirap na bansa, wala namang sapat na yaman ang mga mahihirap para maatim ang pamumuhay na ibinabandera ng mga mayayamang lungsod. ${ }^{25}$ Yaong mga walang pambili ng smartphone ay walang kakayahang makibahagi sa katwirang lungsod, halimbawa.

Malinaw na nagtagumpay ang mga Amerikano sa kanilang proyekto ng edukasyon, sa loob at sa labas ng paaralan. Higit pa sa mga konsepto ng agham at balarila ng Ingles, naturuan nila ang mga Filipino ng mga pagpapahalagang taliwas sa katutubong pamumuhay. Mula sa pagiging susing magsasalba sa kahirapan, naging mamahalin ang edukasyon na lumilikha ng mga banyaga sa sariling lupa.

\section{Edukasyon sa Kasalukuyan bílang Di-mabisang Tagpuan ng Dalawang Katwiran}

Umiiral magpasahanggang ngayon ang kabalintunaan ng edukasyon. Ipinaliwanag ni Emerita S. Quito na ganito ang kaso hindi lang sa Filipinas, kundi pati sa mga dating kolonya. Sapagkat nasanay ang mga kolonisado sa katwiran ng kanilang mananakop, patúloy silang naaakit sa katwirang dayuhan matapos makamtan ang kalayaan ng bayan, samantalang ikinahihiya naman nila ang katutubong katwiran. ${ }^{26}$ Kayâ naman, ang edukasyong tagapagsalba sa kahirapan na nakapagtuturo ng katwirang lungsod (na katwirang banyaga, kung tutuusin) ang siya ring nakapagpapalayo sa katwirang lalawigan, na patúloy na dayuhan ang tingin sa katwiran ng paaralan.

Sinasalamin itong tensiyon ng kasalukuyang pamamayani ng Ingles sa paaralan. Samantalang ito ang pangunahing wika ng edukasyon, hindi naman ito palasak na ginagamit sa pang-araw-araw na búhay. Puna ni

${ }^{24}$ Gilbert and Gugler, Cities, Poverty and Development, 28-30.

${ }^{25}$ Ibid., 30-31.

${ }^{26}$ Emerita S. Quito, "Philosophy of Education for Filipinos," in Philosophy of Education Concerns: Purposes, Content, and Methods of Education, ed. by Celeste O. Botor at Aniceta M. Ortinero (Manila: Rex Bookstore, 1994), 30.

(C) 2016 Noel L. Clemente

http://www.kritike.org/journal/issue 18/clemente june2016.pdf

ISSN 1908-7330

(cc) BY-NC-ND 


\section{EDUKASYON BILANG TAGPUAN}

Constantino, magkaiba ang wika ng pagkatuto sa wika ng komunikasyon. ${ }^{27}$ Sinusubok ng mag-aaral na matutuhan ang katwirang lungsod, samantalang umiiral at nananaig pa rin ang katwirang lalawigan sa labas ng paaralan. Dahil sa tunggaliang ito, hindi produktibo ang pagkatuto sa paaralan. Nananatili ang mag-aaral sa pawang pagsasaulo at pagkakabisa ng impormasyong inuulat ng paaralan. Nakukuntento na siyang masagot ang mga tanong sa eksamen upang makapasa, at maituring na edukado. ${ }^{28} \mathrm{Ni}$ hindi na nag-aabala ang mag-aaral na unawain ang mga leksiyon; hindi naman niya nagagamit ang mga ito sa labas ng paaralan. Sa bansang hindi naman makaagham, halimbawa, saan mo nga ba naman magagamit ang mga kabatirang ito, kung di ka man nagbabalak maging siyentipiko?

Sinasaklaw ng ganitong kabalintunaan ang hanapbuhay pagkatapos ng pormal na edukasyon. Sa mga nagtatrabaho na, nagtatalaban pa rin ang katwirang lungsod-bílang lungsod ang pangunahing tagapagbigay ng hanapbuhay-at ang katwirang lalawigan-na siyang inuuwian ng manggagawa sa kaniyang tahanan. Anumang natututuhan sa trabaho ay hindi naman nagagamit din pag-uwi sa bahay. Kung hindi pamilya ng mga abogado, doktor, o negosyante, ni hindi kadalasang napag-uusapan sa bahay ang mga nagaganap sa trabaho, sapagkat hindi rin naman nauunawaan ang ganoong katwiran.

Napalalalâ ang sitwasyon sa tinatawag nating "brain drain," o ang paglíkas ng mga mahuhusay at matatalino nating kababayan patungo sa ibang bansa, kung saan mas mapapakinabangan nila ang kanilang talento. Nasasariwa lalò ang kabalintunaan ng edukasyon noong panahon ng mga Kastila at Amerikano-sa pamamagitan ng pag-aaral, gumiginhawa ang búhay ng Filipino dahil nagiging isip-lungsod, o isip-banyaga pa nga, kapalít ng pagnanasà niyang lisanin ang báyang nagpaaral sa kaniya. Muli, hindi kasi angkop ang natututuhan sa paaralan para sa katwirang kapakipakinabang sa tahanan.

Samakatwid, namumuhay ang karaniwang estudyante at manggagawa sa dalawang magkalayong katwiran. Pagpasok sa paaralan o opisina, kailangang aralin at pairalin ang katwirang lungsod. Pag-uwi, pansamantalang kinalilimutan ang katwirang ito para manaig ang katwirang lalawigan sa bahay. At sa kasalukuyang estruktura, hindi produktibo ang paggalaw sa dalawang katwirang ito.

${ }^{27}$ Constantino, "The Mis-education of the Filipino," 33.

${ }^{28} \mathrm{Ibid}$.

(C) 2016 Noel L. Clemente

http://www.kritike.org/journal/issue 18/clemente june2016.pdf

ISSN 1908-7330

(c) BY-NC-ND 


\section{Pag-aangkop ng Dalawang Katwiran: Tungo sa Makabayang Edukasyon}

Namalas natin sa ikalawang bahagi ang kabalintunaan ng edukasyon mula noon hanggang ngayon. Sa bahaging ito, tutuklasin natin ang posibilidad ng produktibong interaksiyon ng dalawang katwiran, upang sumaibayo ang edukasyon sa kabalintunaang iniiralan niya.

\section{Pag-aangkop ng Magkaibang Katwiran: Katolisismo bílang Halimbawa}

Mapupuna nating wala tayong katutubong salita para sa "edukasyon," sagisag ng pagiging banyaga ng ganitong sistema. Marapat na kilalanin natin ang pagkadayuhan nitong konsepto at gawaing ito, ngunit maaari pa rin natin itong iangkop ayon sa pangangailangan ng bayan. ${ }^{29}$ Samakatwid, bakâ ang hinahanap natin ay yaong panukala ni Constantino na "edukasyong Filipino," isang makabayang edukasyon. ${ }^{30}$

Maaari nating ihalintulad ang proyekto ng pag-aangkop ng edukasyon sa naganap na pagpapalaganap ng Katolisismo ng mga Kastila. Banyagang katwiran din ang relihiyong ito, ngunit makikita natin sa kasalukuyan ang pagyakap ng malaking bahagdan ng mga Filipino (na may katwirang katutubo) sa pagiging Katoliko. Samakatwid, masasabi natin, kahit papaano, na matagumpay ang interaksiyon ng dalawang katwiran.

Malaking bahagi ng halagahang Filipino ang utang-na-loob at hiya. ${ }^{31}$ Dito nakasalalay ang ating etika. Kayâ mas naging bukás ang ating mga ninuno sa pagtanggap ng Katolisismo nang isalin ito ng mga misyonero sa "May utang-na-loob tayo sa Diyos" at "Kailangan nating magbigay-hiya sa Kaniya." 32 Manapa, itinuturo ng pananampalatayong Katoliko na "alipin táyo ng Panginoong Diyos," kayâ napasunod ng mga fraile ang mga Filipino. ${ }^{33}$ Naging kaakit-akit ang iisang Diyos na nagpapangako ng

${ }^{29}$ Iminungkahi rin ni Demeterio ang ganitong pag-aangkop ng postmodernong teoriyang minana natin sa mga dayuhan sa premodernong konteksto ng Filipinas. See Demeterio, "Our Premodernity and Their Tokens of Postmodernity."

${ }^{30}$ May sariling problematiko ang konsepto ng "makabayan" sapagkat nakasalalay ito sa konsepto ng "bayan," na sa kaso ng Filipinas, ay hindi malinaw. Maaaring talakayin ito sa ibang papel, ngunit ipagpapalagay natin sa papel na ito na ang "makabayan" ay yaong pumapanig sa interes ng mga Filipino, sa halip na mga banyaga.

${ }^{31}$ F. Landa Jocano, Filipino Value System: A Cultural Definition (Quezon City: Punlad Research House, 1997).

32 Vicente L. Rafael, Contracting Colonialism: Translation and Christian Conversion in Tagalog Society under Early Spanish Rule (Quezon City: Ateneo de Manila University Press, 1988), 121-135.

${ }^{33}$ Ibid., 167-169. 
kaligtasan upang ibsan ang takot sa mga katutubong masasamang espiritu (aswang, tikbalang, tiyanak). ${ }^{34}$

Sapagkat lampas na sa saklaw ng papel na ito ang pagpapalaganap ng Katolisismo, sapat na itong maiikling halimbawang nagpapakita ng posibilidad ng produktibong talaban ng dalawang katwiran. Layunin natin sa papel na ito na maisagawa ang naturang pag-aangkop sa katwirang lungsod at katwirang lalawigan na nagtatagpo sa paaralan.

\section{Pag-aangkop ng Katwirang Lungsod at Lalawigan: Tungo sa "Makabayang Edukasyon"}

Siyempre, hindi naman natin agad-agad na maisasagawa ang nasabing pag-aangkop sa kasalukuyang sistema ng edukasyon. Pakatandaang nasa konteksto sila noon ng kolonisasyon; kailangang maunawaan ng mga katutubo ang kanilang relihiyon upang tagumpay nilang maipalaganap ito. Samakatwid, mulát ang mga Kastila sa pagsasagawa ng nasabing pag-aangkop sa dalawang katwiran, na hindi natin masasabi tungkol sa kasalukuyang edukador ng bansa.

Ni hindi nga yata maláy ang karamihan ng mga estudyante sa marahas na talaban ng katwirang paaralan at katwirang tahanan. Maaari nating sabihing bahagi ng katwirang ginagalawan nila ang pangangailangang gumalaw sa dalawang katwirang ito. Tinuturuan táyo ng ating kultura na kailangang mag-aral upang makapaghanapbuhay at kumita at makapamuhay nang matiwasay, samantalang pinaaalalahanan din táyong "lumingon sa pinanggalingan" at alalahanin ang ating mga katutubong paniniwala at mga pampamilyang pagpapahalaga. Kayâ naman, ni hindi natin napagtatantong hindi pala produktibo ang pamamangka natin sa dalawang katwiran.

Samakatwid, ang unang hakbang tungo sa makabayang edukasyon ay ang kamalayang hindi makabayan ang edukasyon natin ngayon. Kailangang mamulat ang mga guro at mga mag-aaral na hindi lubusang produktibo ang nagaganap sa paaralan. Kailangang maging maláy ang mga tao sa ginagalawan nilang katwiran, nang sa gayon ay mapuna rin nila ang marahas na tunggalian ng katwirang lungsod at katwirang lalawigan kung saan sila nakikibahagi.

Nagsisimula ang kamalayan sa katwirang ginagalawan sa kamalayan sa sariling katwiran bilang Filipino. Inilatag ni Quito ang tatlong aspekto ng kamalayang ito na magsisilbing unang hakbang tungo sa

${ }^{34}$ Ibid., 185-196.

(C) 2016 Noel L. Clemente

http://www.kritike.org/journal/issue 18/clemente june2016.pdf

ISSN 1908-7330

(c) BY-NC-ND 
pagrerepaso ng edukasyon. ${ }^{35}$ Una, kailangan ng kamalayan sa ating kasaysayan bílang mga Filipino. Nararapat na maunawaan ng isang Filipino ang pinagdaanan ng kaniyang mga kababayan, mula noong bago dumating ang mga Kastila sa ating kapuluan, hanggang sa pananakop ng mga dayuhan, hanggang sa iba't ibang republikang namahala sa ating bayan hanggang sa kasalukuyan. Ikalawa, kailangan ding maging maláy sa ating pag-uugali, lalò sa yaong mga di-kanais-nais, upang matuklasan ang posibilidad ng pagbabago: mula sa "kanya-kanya" tungo sa pagiging makakapuwa, mula sa pagiging kontento sa "puwede na" tungo sa paghangad ng kagalingan, mula sa "akala ko kasi ..." tungo sa sigasig na umalam. Ikatlo, kailangan ng kamalayan sa mga pagpapahalagang likás na Filipino, tulad ng utang-na-loob, hiya, pakikisama, atbp. Kung babalikan natin si Rodriguez, ang mga pagpapahalagang ito ang batayan ng praktikal na aspekto ng ating katutubong katwiran.

Pagkatapos ng kamalayan sa ating pagka-Filipino, isa sa mga paraan upang maging angkop ang edukasyon (ang katwirang lungsod) sa búhay Filipino (katwirang lalawigan) ay ang paggamit ng katutubong wika. Ani Constantino, "balakid sa pagkatuto ang banyagang wika." 36 Paliwanag niya, hindi nakapag-iisip nang maayos ang mga mag-aaral dahil kailangan pa munang kabisaduhin ang talasalitaan at isalin sa Ingles ang mga konsepto, kaya kadalasang napapako sa pagsasaulo at hindi na umuusad sa malikhaing pag-iisip. ${ }^{37}$ Dahil sa kaibhan ng wika ng pangungusap at wika ng pagkatuto, hindi napagkakasundo ang katwiran ng tahanan at katwiran ng paaralan. Sa gayon, marahil makakatulong ang mother tongue-based education na isinusulong ng K-12. Sanayin muna ang estudyanteng mag-isip sa kanilang katutubong wika sa wikang kinagisnan nila bago ipakilala ang mga banyagang konsepto. ${ }^{38}$ Maaari nating gawing huwaran dito ang edukasyong Hapon. Kapansin-pansing isa na ang kanilang bansa sa mga nangungunang kapangyarihang ekonomiko at teknolohikal sa daigdig, ngunit nananaig ang kanilang pagkamakabayan.

Kailangan ding repasuhin ang nilalaman ng edukasyon, dahil hindi rin naman kapaki-pakinabang ang ilan sa mga inaaral ng estudyante sa kaniyang hanapbuhay kalaunan. Iba ang sitwasyon sa lalawigan o sa katutubong kultura; nag-aaral ang kabataan ng pagsasaka, pangingisda,

${ }^{35}$ Nakabatay itong tatlong aspektong nabanggit sa paliwanag ni Quito sa "historical, behavioral, and axiological aspects of the Filipino," na itinuturing niyang kailangang simulain ng pagbabago sa edukasyon. See Quito, "Philosophy of Education," 32-36.

${ }^{36}$ Constanino, "The Mis-education of the Filipino," 32.

37 Ibid., 33.

${ }^{38}$ Hindi maitatangging layunin ng K-12 na makisabay sa pandaigdigang edukasyon; labingdalawang taon din ang pag-aaral sa karamihan ng mga mauunlad na bansa, kaya bakit hindi natin sila tularan? Mahabang usapan ang pagsusuri sa lahat ng aspekto ng programang K12 , ngunit ang interes lang natin sa ngayon ay ang paggamit ng katutubong wika sa pagtuturo. 
pangangaso, o kahit pangangarpintero, sapagkat ito ang magiging trabaho nila. Sa nahuling kaso, inaaral nila ang katwirang lalawigan na siya ring gagalawan nila sa pagtanda, kayâ walang kabalintunaan ng edukasyon. Sa kaso ng edukasyon sa lungsod, maaaring sabihing mas makatwiran pa ang pag-aaral ng bokasyonal o teknikal na kurso na magagamit sa paghahanapbuhay kaysa ang pag-aaral sa pamantasan kahit na hindi naman talaga kapaki-pakinabang sa trabaho. Sa ibayo ng usapin ng pawang pangangailangan, bakâ maaari ring ituro ang mga alamat at kuwentong katutubo pati na rin makabagong panitikang Filipino, na mas angkop alamin ng mga Filipino kaysa mga klasikong Kanluranin, sapagkat bahagi ito ng ating kultura bilang mga Filipino. Samakatwid, mainam na siyasatin ang kasalukuyang mga kurikulum ng DepEd at CHEd, at tingnan kung akma pa rin ba ang mga asignaturang itinuturo sa pangangailan at pagkakakilanlan ng mga Filipino. Hindi maikakailang kailangan pa rin nilang matutuhan ang agham, sipnayan, kasaysayan, atbp., ngunit bakâ kailangang din namang ituon ang pansin at atensiyon sa mga asignaturang mas pang-Filipino.

Hulí, kailangan ding baguhin ang pamamaraan ng pagturo. Kalakip ng pagkabanyaga ng katwirang lungsod ang pagkabanyaga ng sistema ng edukasyong ipinapamalakad sa paaralan. Hango sa tinuro ng mga Amerikano ang malaking papel na ginagampanan ng mga indibidwal na marka ng mga estudyante sa ating edukasyon. Bukod sa pagsukat ng kakayahan at progreso ng isang mag-aaral, hinihikayat din nito ang kompetisyon-tungo sa isang indibidwalistikong katwiran, kung gayon. Taliwas ito sa katwirang lalawigan na mas makapamilya at makakapuwa, bahagi ng dahilan kung bakit hindi rin produktibo ang pagtakda ng mga marka sa paaralan. Manapa, hinihikayat ang mga mataas na marka dahil sagisag ito ng kagalingan ng isang mag-aaral, na siyang hinahanap ng mga kompanya (ng lungsod, siyempre!). Samakatwid, lalòng pinahahalagahan ang mataas na marka kaysa tunay na pagkatuto; marka ang nagiging batayan ng natutuhan sa halip na tagagabay lámang nito. Makatutulong sa pagaangkop ng edukasyon sa pangangailangang Filipino ang pagbibigay ng sistema ng ebalwasyon na mas angkop sa mga Filipino. Bakâ kahit mga eksamen ay kailangan hubugin upang matingnan at masipat ang tunay na antas ng pagkaunawa ng estudyante, sa halip na magsilbing paligsahan lámang na kakalimutan ang nilalaman pagkatapos manalo.

\section{Pangwakas}

Batid kong hindi ganap na kongkreto ang mga iminungkahi kong hakbang tungo sa makabayang edukasyon. Sa katunayan, marahil malayo pa táyo sa pagsasaibayo sa kabalintunaan ng edukasyon. Masyadong malalim ang mga ugat na naitanim ng mga Kastila at ng mga Amerikano, na lumilok

(C) 2016 Noel L. Clemente http://www.kritike.org/journal/issue 18/clemente june2016.pdf ISSN 1908-7330

(c) BY-NC-ND 
sa isip-lungsod na pinapalaganap ng paaralan, kayâ kailangan din ng panahon bago natin malampasan ang kanilang paggayuma sa ating kultura. Gayunpaman, sa mga munting hakbang, tulad ng mga naimungkahi kong kamalayan sa suliranin na susundan ng pagbabago sa wika, nilalaman, at pamamaraan ng pagturo, marahan nating mabubunot ang mga ugat na ito, tungo sa isang edukasyong angkop sa katwirang Filipino. Kung matagumpay na magkasundo ang dalawang katwirang nagtatagpo sa paaralan, magkakaroon tayo ng mga Filipinong bagaman nahasikan ng mga dagta ng banyaga, ay nakaugat sa katutubo at Filipinong kaisipan. Manapa, isang malaking hakbang itong pagkakasundo ng lungsod at lalawigan tungo sa pagkakaisa ng mga Filipino bílang isang bayan. ${ }^{39}$

Department of Philosophy, Ateneo de Manila University, Philippines

\section{References}

Abinales, Patricio N. and Donna J. Amoroso, State and Society in the Philippines (Mandaluyong City: Anvil Press, 2005).

Demeterio, F.P.A. III, "Our Premodernity and Their Tokens of Postmodernity: Reflections on the Philippine Condition," in Academia, <https://www.academia.edu/7340227/Our Premodernity and their Tokens of Postmodernity Reflections on the Philippin e Condition>, 21 March 2016.

"The Primitivization of the Indio Mind and the Explosion of Rationalities: The Politics of Knowledge in the Spanish Colonial Philippines," in Academia, <https://www.academia.edu/7340242/ The Primitivization of the Indio Mind and the Explosion of Ra tionalities the Politics of Knowledge in the Spanish Colonial Ph ilippines $>, 21$ March 2016.

Constantino, Renato, "The Mis-education of the Filipino," in Journal of Contemporary Asia, 1:1 (1970).

Gilbert, Alan and Josef Gugler, Cities, Poverty and Development: Ubranization in the Third World (New York: Oxford University Press, 1992).

Jocano, F. Landa, Filipino Value System: A Cultural Definition (Quezon City: Punlad Research House, 1997).

Mabini, Apolinario, Ang Rebolusyong Filipino, trans. by Michael M. Coroza (Manila: Pambansang Komisyon sa Kultura at Sining, 2015).

\footnotetext{
${ }^{39}$ Nagpapasalamat ako kina Dr. Guss Rodriguez at Dr. Jack Cleofas sa kanilang mga ideya na nakatulong sa pagsusulat at pagrerebisa ng papel na ito. Nais ko ring pasalamatan ang patnugutan ng Kritike, pati na rin ang nag-referee sa aking manuskrito, na nagbigay ng mga mahahalagang mungkahi upang linangin at paunlarin ang unang bersiyon ng aking papel. 


\section{EDUKASYON BILANG TAGPUAN}

Quito, Emerita S., "Philosophy of Education for Filipinos," in Philosophy of Education Concerns: Purposes, Content, and Methods of Education, ed. by Celeste O. Botor at Aniceta M. Ortinero (Manila: Rex Bookstore, 1994).

Rafael, Vicente L., Contracting Colonialism: Translation and Christian Conversion in Tagalog Society under Early Spanish Rule (Quezon City: Ateneo de Manila University Press, 1988).

Rodriguez, Agustin Martin, May Laro Ang Diskurso ng Katarungan (Quezon City: Ateneo de Manila University Press, 2014).

(C) 2016 Noel L. Clemente

http://www.kritike.org/journal/issue 18/clemente june2016.pdf

ISSN 1908-7330

(cc) BY-NC-ND 